\title{
Association Between Red Blood Cell Distribution Width-to-Albumin Ratio and Prognosis of Patients with Aortic Aneurysms
}

\author{
Jianyun Long \\ Xupin Xie \\ Dong $X u$ \\ Changpin Huang \\ Yongchang Liu \\ Xiaohu Meng \\ Xuchao Cai \\ Xin Fang
}

Department of Vascular Surgery, Affiliated Hangzhou First People's Hospital, Zhejiang University School of Medicine, Hangzhou, Zhejiang, 3100I4, People's Republic of China
Correspondence: Xin Fang

Department of Vascular Surgery, Affiliated Hangzhou First People's Hospital,

Zhejiang University School of Medicine

Hangzhou, Zhejiang, 310014, People's

Republic of China

Tel +86 57l-56005600

Email hzfhfx@I26.com
Objective: Red blood cell distribution width (RDW) is a predictor of adverse outcomes in aortic aneurysms. Recent recommendations suggest that combining RDW with other biomarkers could yield better results. We, therefore, propose evaluating the biomarker of vascular aging, albumin with RDW to predict the risk of aortic aneurysms. This study aims to explore whether the combination of RDW with albumin can effectively predict the prognosis of aortic aneurysm patients.

Methods: This retrospective cohort study was conducted among adults (age $>18$ ) with aortic aneurysms in the Medical Information Mart for Intensive Care Database III V1.4 (MIMICIII). RAR was measured according to the red blood cell distribution width and albumin. The primary outcome was the 30-day mortality rate, and the secondary outcome was the 90-day and one-year mortality rates. Estimation of hazard ratios (HR) was obtained from Cox regression models for all-cause mortality related to red cell distribution width-to-albumin ratio (RAR) values.

Results: In total, 312 patients were involved, with an average age of $74.9 \pm 10.9$ years and an average RAR value of $5.4 \pm 1.6 \mathrm{~mL} / \mathrm{g}$. In 30 days for all-cause mortality, the $\mathrm{HR}(95 \% \mathrm{CI})$ in the highest RAR group $(>5.8 \mathrm{~mL} / \mathrm{g})$ in tertiles was $2.54(1.25,5.14)$ in the unadjusted model, with a significant difference compared with the reference group $(\mathrm{P}<0.05)$. After adjusting for race, gender and age, there was still a correlation $(\mathrm{P}<0.05)$, and the HR $(95 \%$ $\mathrm{CI})$ was $2.51(1.23,5.10)$. Further adjustment of possible covariates showed similar correlation in model $3(\mathrm{P}<0.05)$, and HR $(95 \% \mathrm{CI})$ was $2.66(1.17,6.01)$. Multivariable logistic regression shows that RAR is an independent risk factor for the outcome of aortic aneurysms after adjusting the covariates. In the subgroup analysis, we analyzed the patient's complications, and no significant interaction was observed.

Conclusion: RAR is a risk factor for patients with aortic aneurysms. However, more indepth research is warranted to further analyze and substantiate our findings on the role of RAR in aortic aneurysm patients.

Keywords: red blood cell distribution width-albumin ratio, aortic aneurysms, retrospective cohort study, MIMIC-III

\section{Introduction}

The definition of an aneurysm is a blood vessel expansion of greater than 1.5 times the usual size, among which TAAs (thoracic aortic aneurysms) and AAAs (abdominal aortic aneurysms) are the most common in clinical practice and also the main focus of current research works. ${ }^{1}$ The incidence of aortic aneurysms increases with age. The incidence is $4-8 \%$ for males older than 60 years, while it is $0.5-2 \%$ for 
females. In a recent study, the prevalence rate was $6 \%$ among men aged 65-69 and 17\% among men aged 70$74 .^{2}$ In the industrialized world, $1.3 \%$ of all abdominal aortic aneurysm deaths were among those aged 65 to 85 years old. This disease is the 13th biggest cause of death in the United States. ${ }^{3}$ The total mortality rate varies from $65 \%$ to $85 \%$ in patients with ruptured abdominal aortic aneurysms, ${ }^{4,5}$ and about half of the deaths occurred before the patient arrived in the operating room. ${ }^{6}$

The incidence of aortic aneurysms is high, and the mortality rate of aortic aneurysm patients is even higher. How to assess the severity and prognosis of patients is a major issue in clinical practice. Ultrasound and CT are commonly used clinically to assess the severity of a patient's condition. ${ }^{7}$ Previous studies have revealed three risk scores are commonly used to evaluate clinical outcomes in patients with AAA: the Medicare risk score ${ }^{8}$ the Vascular Study Group of New England risk score ${ }^{9}$ and the Glasgow aneurysm score. ${ }^{10}$ However, these risk scores are only determined after surgery and are thus not satisfactory as a predictive tool in clinical practice. The pathophysiology of aortic aneurysms is poorly understood, but many studies have shown that inflammation plays an important role in the development of aortic aneurysms. ${ }^{2,11}$ Recently, the red blood cell distribution width (RDW) has been identified as a new prognostic factor under many pathophysiological conditions, including cardiovascular and cerebrovascular diseases and inflammation. ${ }^{12,13}$ Recent studies ${ }^{14,15}$ have also suggested that RDW is a predictor of adverse outcomes in aortic aneurysms. Recent recommendations suggest combining RDW with other biomarkers. Serum albumin level was shown to be associated with cardiovascular mortality. ${ }^{16}$ Albumin is also associated with anti-inflammatory activity, reduction of oxidative stress and inhibition of endothelial apoptosis. So, whether RDW combined with albumin can effectively predict the prognosis of patients with aneurysms is a question that this study would like to explore.

\section{Methods}

\section{Study Population}

MIMIC-III is a huge single-center database that contains information about patients who have been admitted to the intensive care unit (ICU) of a large tertiary care hospital. MIMIC-III contains data on 53,423 adult patients (16 years of age or older) admitted to the ICU between 2001 and 2012. This database contains basic information about patients, as well as survival data and treatment specifics. ${ }^{17}$ MIMIC-III has been approved by the Institutional Review Boards of both MIT (Massachusetts Institute of Technology) and BIDMC.

To screen the patients for our study, we used the following inclusion criteria: (1) patients diagnosed with the thoracic aortic aneurysm or abdominal aortic aneurysm; (2) length of hospital stay $>2$ days; ( 3 ) age $\geq 18$ years. The exclusion criteria were as follows: (1) age $<18$ years; (2) more than $10 \%$ of the patient's individual data was missing; (3) outliers: the value exceeds the mean \pm 3 Standard Deviation (SD). The first ICU admission record was included for patients admitted more than once.

\section{Covariates}

The data were extracted from MIMIC-III (V1.4), including demographic data, basic vital signs, scoring system, basic laboratory parameters, and comorbidities. Demographic information comprised race, gender and age. Complications included AF (atrial fibrillation), CHF (congestive heart failure), CHD (coronary heart disease), renal failure, respiratory failure and pneumonia. Laboratory parameters included RDW, albumin, white blood cell (WBC) count, platelet, hemoglobin, hematocrit, APTT, INR, PT, creatinine, urea nitrogen, serum sodium, serum potassium, anion gap, bicarbonate, bilirubin and glucose in the first 24 hours. Whether mechanical ventilation had been used was also included.

\section{Assessment of RAR}

Venous blood samples were taken from the subjects within the first $24 \mathrm{~h}$ of admission. The RAR was calculated as the ratio of the RDW to albumin. To reveal the exact association between these hematological parameters and the endpoints, we treated them as tertiles, quartiles and continuous variables.

\section{Outcomes}

The study endpoints were 30-day, 90-day, and one-year mortality rates. The observation time was from the patient's first admission to the hospital until death.

\section{Statistical Analyses}

Baseline characteristics were divided into tertiles by RAR $(<4.5 \mathrm{~mL} / \mathrm{g}, 4.5-5.8 \mathrm{~mL} / \mathrm{g}$ and $>5.8 \mathrm{~mL} / \mathrm{g})$. Fisher's exact test or Chi-square test has been used to evaluate categorical variables that were reported as a frequency (\%). Continuous variables were represented by the mean (SD), 
and Kruskal-Wallis $H$-test or variance analysis has been utilized for comparing the various groups. The relationship between RAR and all-cause mortality has been investigated using Cox proportional hazard regression, and the results were presented as an HR (hazard ratio) with a $95 \%$ CI (confidence interval). For each endpoint, three multivariate analytic models have been developed and were used for testing. In model 1 , the covariates were not adjusted; in model 2, the covariates included race, gender and age; in model 3, renal failure, respiratory failure, pneumonia, platelet, PT, anion gap, bicarbonate and heart rate were further adjusted. The choice of covariates was based on the estimated value of impact $>10 \%$. Subgroup analysis was performed to explore if the association differed for subgroups classified by different complications, including AF (atrial fibrillation), CHF (congestive heart failure), CHD (coronary heart disease), renal failure, respiratory failure and pneumonia.

EmpowerStats (http://www.empowerstats.com/cn/) has been utilized for all statistical analyses. A P-value $<0.05$ (2-sided) is considered statistically significant.

\section{Characteristics of Patients}

Baseline characteristics are shown in Table 1. In total, 312 patients met our inclusion criteria and were selected, including 122 women and 190 men, with an average age of $74.9 \pm 10.9$ years and an average RAR of $5.4 \pm 1.6 \mathrm{~mL} /$ g. Based on the RAR value, the participants in this study were divided into tertiles $(<4.5 \mathrm{~mL} / \mathrm{g}, 4.5-5.8 \mathrm{~mL} / \mathrm{g}$ and $>5.8 \mathrm{~mL} / \mathrm{g}$ ). Patients with higher RAR had a faster heart rate, higher urea nitrogen and white blood cell counts but lower hemoglobin and hematocrit. The prevalence of coronary heart disease (CHD), renal failure and pneumonia was also significantly more frequent in high RAR patients. Patients with higher RAR also had an increased tendency of mechanical ventilation use. (All $\mathrm{P}<0.05$ ).

\section{Association Between RAR and Mortality}

Following the correction for potential confounders, several models were developed to assess the correlations between RAR and the outcomes of patients with aortic aneurysms. Table 2 shows the outcomes of these connections based on the data collected. When RAR was modeled as a continuous variable, the 30-day all-cause mortality rate in model 1, model 2, and model 3 had HR values of 1.30 , 1.32 , and 1.39 , respectively. For 90-day and one-year allcause mortality rates, the same association was detected with RAR. In 30 days all-cause mortality, the HR (95\%
CI) in the highest RAR group $(>5.8 \mathrm{~mL} / \mathrm{g})$ in tertiles was $2.54(1.25,5.14)$ in the unadjusted model, with a significant difference compared with the reference group $(\mathrm{P}<0.05)$. After adjusting for race, gender and age, the connection still existed $(\mathrm{P}<0.05)$, and the HR $(95 \%$ CI $)$ was $2.51(1.23,5.10)$. Further adjustment of possible covariates showed similar correlation in model 3 $(\mathrm{P}<0.05)$, HR $(95 \% \mathrm{CI})$ was $2.66(1.17,6.01)$. All $P$ values were less than 0.05 , indicating that RAR had a significant positive correlation with 30-day all-cause mortality. The same correlation was present between 90day and one-year all-cause mortality rates. When RAR values were divided into quintiles, similar correlations were also observed.

Subgroup analysis results are shown in Table 3. In the subgroup analysis, we analyzed the patient's complications, and no significant interaction was observed. This shows that the results of this article have good stability in patients with aortic aneurysms.

\section{Discussion}

Aortic aneurysms, when ruptured or symptomatic, are related to a significantly higher rate of short- and intermediate-term death, according to recent clinical reports. ${ }^{18}$ It is difficult to identify high-risk patients upon admission to the emergency department, although numerous clinical risk indicators for poor outcomes were identified in this patient population. ${ }^{19}$ The diagnosis may be delayed considerably because of the silent clinical history of thoracic and abdominal aortic aneurysms. Therefore, the condition and prognosis of aortic aneurysm patients must be promptly and accurately assessed upon admission. An ideal biomarker should either be capable of detecting or reflecting the existence of subclinical aneurysms. Herein, we are the first to investigate the link between RAR and the prognosis of patients with thoracic or abdominal aortic aneurysms. We found that elevated RAR was significantly related to an increased risk of all-cause mortality of patients with thoracic or abdominal aortic aneurysm. Aortic aneurysms are often accompanied by a poor prognosis, and using a simple non-invasive biological marker such as RAR can help physicians better assess and predict the prognosis of aortic aneurysm in the future.

The formation and development of aortic-related disease involve the inflammation processes pathophysiologically. ${ }^{20,21}$ Aneurysm development is linked to a chronic aortic wall inflammation, which may be assessed by increasing IL- 6 and CRP $^{22}$ levels. The 
Table I Baseline Characteristics of the Study Population

\begin{tabular}{|c|c|c|c|c|}
\hline \multirow[t]{2}{*}{ Characteristics } & \multicolumn{3}{|c|}{ RA Level, mL/g } & \multirow[t]{2}{*}{$P$ value } \\
\hline & $<4.5$ & $4.5-5.8$ & $>5.8$ & \\
\hline$N$ & 104 & 104 & 104 & \\
\hline Age, years & $73.30 \pm 12.52$ & $76.85 \pm 9.25$ & $74.61 \pm 10.35$ & 0.058 \\
\hline $\begin{array}{l}\text { Sex, n (\%) } \\
\text { Female } \\
\text { Male }\end{array}$ & $\begin{array}{l}37(35.58) \\
67(64.42)\end{array}$ & $\begin{array}{l}42(40.38) \\
62(59.62)\end{array}$ & $\begin{array}{l}43(4 I .35) \\
6 I(58.65)\end{array}$ & 0.659 \\
\hline $\begin{array}{c}\text { Race, n (\%) } \\
\text { White } \\
\text { Black } \\
\text { Other }\end{array}$ & $\begin{array}{c}79(75.96) \\
7(6.73) \\
18(17.31)\end{array}$ & $\begin{array}{c}85(81.73) \\
5(4.8 I) \\
14(13.46)\end{array}$ & $\begin{array}{c}86(82.69) \\
2(1.92) \\
16(15.38)\end{array}$ & 0.469 \\
\hline $\begin{array}{l}\text { Vital signs } \\
\text { Heart rate, beats/minute } \\
\mathrm{SBP}, \mathrm{mmHg} \\
\mathrm{DBP}, \mathrm{mmHg} \\
\mathrm{MBP}, \mathrm{mmHg} \\
\text { Respiratory rate, times/minute } \\
\mathrm{T},{ }^{\circ} \mathrm{C} \\
\mathrm{SPO}_{2}, \%\end{array}$ & $\begin{array}{c}79.05 \pm 15.58 \\
119.67 \pm 15.72 \\
60.42 \pm 10.97 \\
78.56 \pm 11.06 \\
18.77 \pm 3.26 \\
36.74 \pm 0.58 \\
96.96 \pm 1.88\end{array}$ & $\begin{array}{c}81.94 \pm 15.00 \\
117.24 \pm 15.21 \\
59.88 \pm 10.00 \\
77.57 \pm 10.18 \\
18.64 \pm 3.46 \\
36.66 \pm 0.63 \\
97.20 \pm 1.76\end{array}$ & $\begin{array}{c}86.02 \pm 13.89 \\
\mid 15.37 \pm 13.62 \\
57.52 \pm 8.74 \\
75.64 \pm 9.19 \\
19.05 \pm 3.73 \\
36.70 \pm 0.65 \\
97.17 \pm 1.96\end{array}$ & $\begin{array}{l}0.003 \\
0.115 \\
0.085 \\
0.111 \\
0.687 \\
0.623 \\
0.602\end{array}$ \\
\hline $\begin{array}{l}\text { Laboratory parameters } \\
\text { Anion gap, mmol/L } \\
\text { Serum creatinine, mg/dL } \\
\text { Glucose, mg/dL } \\
\text { Hematocrit, \% } \\
\text { Hemoglobin, g/dl } \\
\text { PTT, s } \\
\text { INR } \\
\text { PT, s } \\
\text { BUN, mg/dl } \\
\text { Platelet counts, } 10^{9} / \mathrm{L} \\
\text { WBC counts, } 10^{9} / \mathrm{L} \\
\text { RA, mL/g } \\
\text { RDW, \% } \\
\text { Serum albumin, g/dL }\end{array}$ & $\begin{array}{c}14.80 \pm 3.66 \\
1.37 \pm 0.96 \\
144.96 \pm 55.63 \\
34.78 \pm 5.8 \mid \\
11.72 \pm 2.07 \\
35.97 \pm 19.66 \\
1.55 \pm 0.92 \\
16.59 \pm 7.90 \\
25.76 \pm \mid 8.23 \\
231.80 \pm 96.01 \\
11.27 \pm 4.97 \\
3.83 \pm 0.4 \mid \\
14.19 \pm 1.02 \\
3.73 \pm 0.39\end{array}$ & $\begin{array}{c}14.73 \pm 4.32 \\
1.70 \pm 1.59 \\
155.12 \pm 102.50 \\
32.23 \pm 5.94 \\
10.73 \pm 1.97 \\
40.00 \pm 24.07 \\
1.62 \pm 1.02 \\
16.73 \pm 7.74 \\
30.62 \pm 18.68 \\
198.23 \pm 94.93 \\
11.39 \pm 7.02 \\
5.20 \pm 0.36 \\
15.53 \pm 1.54 \\
3.00 \pm 0.33\end{array}$ & $\begin{array}{c}14.27 \pm 4.96 \\
1.77 \pm 1.40 \\
139.62 \pm 52.38 \\
30.33 \pm 4.83 \\
10.09 \pm 1.70 \\
41.94 \pm 26.08 \\
1.60 \pm 0.89 \\
16.82 \pm 7.10 \\
32.38 \pm 21.44 \\
213.14 \pm \mid 44.63 \\
\mid 4.63 \pm 10.23 \\
7.13 \pm 1.29 \\
16.32 \pm 2.21 \\
2.35 \pm 0.46\end{array}$ & $\begin{array}{c}0.642 \\
0.077 \\
0.308 \\
<0.001 \\
<0.001 \\
0.183 \\
0.874 \\
0.976 \\
0.042 \\
0.107 \\
0.002 \\
<0.001 \\
<0.001 \\
<0.001\end{array}$ \\
\hline $\begin{array}{l}\text { Comorbidities, n (\%) } \\
\text { CHF } \\
\text { AF } \\
\text { Renal disease } \\
\text { CAD } \\
\text { Pneumonia }\end{array}$ & $\begin{array}{l}22(21.15) \\
40(38.46) \\
16(15.38) \\
47(45.19) \\
18(17.31)\end{array}$ & $\begin{array}{l}20(19.23) \\
49(47.12) \\
25(24.04) \\
30(28.85) \\
32(30.77)\end{array}$ & $\begin{array}{l}13(12.50) \\
39(37.50) \\
25(24.04) \\
35(33.65) \\
32(30.77)\end{array}$ & $\begin{array}{l}0.228 \\
0.300 \\
0.211 \\
0.041 \\
0.039\end{array}$ \\
\hline $\begin{array}{l}\text { Mortality, n (\%) } \\
\text { 30-day } \\
\text { 90-day } \\
\text { One year }\end{array}$ & $\begin{array}{l}11(10.58) \\
13(12.50) \\
21(20.19)\end{array}$ & $\begin{array}{l}13(12.50) \\
18(17.31) \\
32(30.77)\end{array}$ & $\begin{array}{l}26(25.00) \\
38(36.54) \\
45(43.27)\end{array}$ & $\begin{array}{c}0.009 \\
<0.001 \\
0.002\end{array}$ \\
\hline
\end{tabular}

Abbreviations: RA, the ratio of red cell volume distribution width to albumin; SBP, systolic blood pressure; DBP, diastolic blood pressure; MAP, mean arterial pressure; RDW, red cell volume distribution width; APTT, activated partial thromboplastin time; PT, prothrombin time; INR, international normalized ratio; Vent., ventilation; CHF, congestive heart failure; $\mathrm{AF}$, atrial fibrillation; $\mathrm{CAD}$, coronary artery disease. 
Table 2 HR for All-Cause Mortality Across Groups of RAR

\begin{tabular}{|c|c|c|c|c|c|c|}
\hline \multirow[t]{2}{*}{ Clinical Outcomes } & \multicolumn{2}{|c|}{ Model I ${ }^{a}$} & \multicolumn{2}{|c|}{ Model $2^{b}$} & \multicolumn{2}{|c|}{ Model $3^{c}$} \\
\hline & HR (95\% Cl) & $P$ value & HR (95\% Cl) & $P$ value & HR (95\% Cl) & $P$ value \\
\hline \multicolumn{7}{|l|}{ 30-day mortality } \\
\hline RAR & $1.30(1.12,1.50)$ & 0.0006 & $1.32(1.14,1.54)$ & 0.0003 & $1.39(1.14,1.70)$ & 0.0012 \\
\hline \multicolumn{7}{|l|}{ RAR tertiles } \\
\hline$<4.5$ & 1.0 & & 1.0 & & 1.0 & \\
\hline $4.5-5.8$ & $1.18(0.53,2.64)$ & 0.6843 & $1.06(0.47,2.36)$ & 0.8929 & $1.21(0.52,2.83)$ & 0.6614 \\
\hline$>5.8$ & $2.54(1.25,5.14)$ & 0.0096 & $2.51(1.23,5.10)$ & 0.0112 & $2.66(1.17,6.01)$ & 0.0190 \\
\hline$P_{\text {for trend }}$ & & 0.0048 & & 0.0048 & & 0.0099 \\
\hline \multicolumn{7}{|l|}{ RAR quintiles } \\
\hline$<4$ & 1.0 & & 1.0 & & 1.0 & \\
\hline $4-4.8$ & $0.93(0.30,2.87)$ & 0.8947 & $0.92(0.29,2.86)$ & 0.8828 & $1.12(0.32,3.88)$ & 0.8594 \\
\hline $4.8-5.5$ & $1.30(0.45,3.75)$ & 0.6253 & $1.22(0.42,3.52)$ & 0.7164 & $1.39(0.43,4.46)$ & 0.5783 \\
\hline $5.5-6.4$ & $2.34(0.90,6.08)$ & 0.0820 & $2.26(0.87,5.92)$ & 0.0955 & $2.49(0.8 I, 7.66)$ & 0.1109 \\
\hline$>6.4$ & $2.83(\mathrm{I} .1 \mathrm{I}, 7.25)$ & 0.0295 & $3.13(1.21,8.07)$ & 0.0182 & $3.49(1.10,11.05)$ & 0.0336 \\
\hline$P_{\text {for trend }}$ & & 0.0026 & & 0.0013 & & 0.0070 \\
\hline \multicolumn{7}{|l|}{ 90-day mortality } \\
\hline RAR & $1.34(1.19,1.52)$ & $<0.0001$ & $1.38(1.22,1.57)$ & $<0.0001$ & $1.46(1.24,1.72)$ & $<0.0001$ \\
\hline \multicolumn{7}{|l|}{ RAR tertiles } \\
\hline$<4.5$ & 1.0 & & 1.0 & & 1.0 & \\
\hline $4.5-5.8$ & $1.40(0.69,2.85)$ & 0.3569 & $1.26(0.6 \mathrm{I}, 2.58)$ & 0.5290 & $1.57(0.74,3.34)$ & 0.2400 \\
\hline$>5.8$ & $3.28(1.75,6.16)$ & 0.0002 & $3.34(1.77,6.30)$ & 0.0002 & $3.78(1.85,7.74)$ & 0.0003 \\
\hline$P_{\text {for trend }}$ & & $<0.0001$ & & $<0.0001$ & & $<0.0001$ \\
\hline \multicolumn{7}{|l|}{ RAR quintiles } \\
\hline$<4$ & 1.0 & & 1.0 & & 1.0 & \\
\hline $4-4.8$ & $0.93(0.33,2.66)$ & 0.8979 & $0.91(0.32,2.61)$ & 0.8658 & I.II $(0.36,3.44)$ & 0.8515 \\
\hline $4.8-5.5$ & I.7I $(0.67,4.35)$ & 0.2587 & $1.57(0.6 \mathrm{I}, 4.0 \mathrm{I})$ & $0.346 \mathrm{I}$ & $2.07(0.75,5.75)$ & 0.1622 \\
\hline $5.5-6.4$ & $2.53(1.05,6.11)$ & 0.0384 & $2.51(1.04,6.08)$ & 0.0412 & $3.12(1.15,8.45)$ & 0.0250 \\
\hline$>6.4$ & $4.15(1.80,9.57)$ & 0.0008 & $4.68(2.02,10.86)$ & 0.0003 & $5.61(2.09,15.03)$ & 0.0006 \\
\hline$P_{\text {for trend }}$ & & $<0.0001$ & & $<0.0001$ & & $<0.0001$ \\
\hline \multicolumn{7}{|l|}{ One year mortality } \\
\hline RAR & $1.28(1.15,1.43)$ & $<0.0001$ & $1.31(1.17,1.47)$ & $<0.0001$ & $1.42(1.23,1.64)$ & $<0.0001$ \\
\hline \multicolumn{7}{|l|}{ RAR tertiles } \\
\hline$<4.5$ & 1.0 & & 1.0 & & 1.0 & \\
\hline $4.5-5.8$ & $1.58(0.91,2.74)$ & 0.1047 & $\mathrm{I} .38(0.79,2.4 \mathrm{I})$ & 0.2512 & $1.64(0.92,2.92)$ & 0.0922 \\
\hline$>5.8$ & $2.56(1.52,4.29)$ & 0.0004 & $2.56(1.52,4.31)$ & 0.0004 & $2.96(1.65,5.30)$ & 0.0003 \\
\hline$P_{\text {for trend }}$ & & 0.0002 & & 0.0002 & & 0.0002 \\
\hline \multicolumn{7}{|l|}{ RAR quintiles } \\
\hline$<4$ & 1.0 & & 1.0 & & 1.0 & \\
\hline $4-4.8$ & $0.93(0.42,2.08)$ & 0.8650 & $0.89(0.40,1.99)$ & 0.7811 & $1.04(0.45,2.42)$ & 0.9296 \\
\hline $4.8-5.5$ & $1.72(0.84,3.52)$ & 0.1374 & $1.56(0.76,3.20)$ & 0.2288 & $1.80(0.83,3.91)$ & 0.1363 \\
\hline $5.5-6.4$ & $2.09(1.04,4.20)$ & 0.0387 & $2.03(1.01,4.10)$ & 0.0472 & $2.57(1.18,5.57)$ & 0.0171 \\
\hline$>6.4$ & $3.14(1.61,6.12)$ & 0.0008 & $3.48(I .77,6.8 I)$ & 0.0003 & 4.15 (1.91, 9.02) & 0.0003 \\
\hline$P_{\text {for trend }}$ & & $<0.0001$ & & $<0.0001$ & & $<0.0001$ \\
\hline
\end{tabular}

Notes: a, b and c were derived from Cox proportional hazards regression models: ${ }^{\mathrm{a} C}$ Covariates were adjusted for nothing; ${ }^{\mathrm{b}}$ Covariates were adjusted for age, sex and ethnicity; 'Covariates were adjusted for age, sex, ethnicity, heart rate, prothrombin time, renal disease, pneumonia, anion gap, bicarbonate, platelet.

Abbreviations: $\mathrm{HR}$, hazard ratio; $\mathrm{Cl}$, confidence interval; $\mathrm{RA}$, the ratio of RDW to albumin.

correlation of RDW with inflammatory markers involving hs-CRP was demonstrated and acknowledged to be a risk factor for cardiovascular adverse events. ${ }^{23}$ High concentrations of RDW were found to result in an increased risk of AAA. ${ }^{24}$ Albumin is a negative acute-phase protein with antioxidant properties in contrast to $\mathrm{CRP} .{ }^{25}$ Inflammatory activities are inversely associated with albumin-synthesis rate, which raises blood viscosity, aggregation and platelet 
Table 3 Subgroup Analysis of the Associations Between 30-Day All-Cause Mortality and the RAR Level

\begin{tabular}{|c|c|c|c|c|c|}
\hline & \multirow[t]{2}{*}{ No. of Patients } & \multicolumn{3}{|c|}{ RAR Level, mL/g } & \multirow[t]{2}{*}{$P$ for Interaction } \\
\hline & & $<4.5$ & $4.5-5.8$ & $>5.8$ & \\
\hline $\begin{array}{l}\text { Age } \\
\qquad \begin{array}{l}<76.7 \\
\geq 76.7\end{array}\end{array}$ & $\begin{array}{l}156 \\
156\end{array}$ & $\begin{array}{l}1.0 \\
1.0\end{array}$ & $\begin{array}{c}2.00(0.33,11.95) \\
0.83(0.34,2.04)\end{array}$ & $\begin{array}{c}4.46(0.95,21.00) \\
2.04(0.92,4.55)\end{array}$ & 0.8231 \\
\hline $\begin{array}{l}\text { Sex } \\
\qquad \text { Female } \\
\text { Male }\end{array}$ & $\begin{array}{l}122 \\
190\end{array}$ & $\begin{array}{l}1.0 \\
1.0\end{array}$ & $\begin{array}{l}0.71(0.22,2.32) \\
I .76(0.58,5.39)\end{array}$ & $\begin{array}{c}1.13(0.39,3.25) \\
4.50(1.67,12.11)\end{array}$ & 0.1497 \\
\hline $\begin{array}{l}\text { CHF } \\
\text { No } \\
\text { Yes } \\
\text { AF } \\
\text { No } \\
\text { Yes }\end{array}$ & $\begin{array}{l}257 \\
55 \\
184 \\
128\end{array}$ & $\begin{array}{l}1.0 \\
1.0 \\
1.0 \\
1.0\end{array}$ & $\begin{array}{l}I .43(0.5 \mathrm{I}, 3.97) \\
0.4 \mathrm{I}(0.05,3.1 \mathrm{I}) \\
\mathrm{I} .09(0.29,4.12) \\
\mathrm{I} .09(0.34,3.56)\end{array}$ & $\begin{array}{c}3.67(1.45,9.28) \\
1.22(0.19,8.02) \\
3.28(1.05,10.28) \\
2.67(0.83,8.59)\end{array}$ & $\begin{array}{l}0.5632 \\
0.9806\end{array}$ \\
\hline $\begin{array}{l}\text { Renal disease } \\
\text { No } \\
\text { Yes }\end{array}$ & $\begin{array}{c}246 \\
66\end{array}$ & $\begin{array}{l}1.0 \\
1.0\end{array}$ & $\begin{array}{l}1.77(0.60,5.21) \\
0.21(0.04,1.13)\end{array}$ & $\begin{array}{c}3.68(1.34,10.08) \\
1.17(0.27,5.14)\end{array}$ & 0.1190 \\
\hline $\begin{array}{l}\text { CAD } \\
\text { No } \\
\text { Yes }\end{array}$ & $\begin{array}{l}200 \\
112\end{array}$ & $\begin{array}{l}1.0 \\
1.0\end{array}$ & $\begin{array}{l}\text { I.I7 }(0.36,3.84) \\
\text { I.II }(0.29,4.29)\end{array}$ & $\begin{array}{c}4.13(1.40,12.21) \\
1.58(0.45,5.52)\end{array}$ & 0.4689 \\
\hline $\begin{array}{l}\text { Pneumonia } \\
\text { No } \\
\text { Yes }\end{array}$ & $\begin{array}{c}230 \\
82\end{array}$ & $\begin{array}{l}1.0 \\
1.0\end{array}$ & $\begin{array}{l}0.74(0.25,2.18) \\
1.84(0.31,10.85)\end{array}$ & $\begin{array}{c}2.30(0.89,5.93) \\
3.97(0.70,22.63)\end{array}$ & $0.597 \mid$ \\
\hline
\end{tabular}

Notes: HR $(95 \% \mathrm{Cl})$ were derived from Cox proportional hazards regression models. Covariates were adjusted as in model I (Table 2).

Abbreviations: $\mathrm{HR}$, hazard ratio; $\mathrm{Cl}$, confidence interval; $\mathrm{RA}$, the ratio of RDW to albumin; $\mathrm{CHF}$, congestive heart failure; $\mathrm{AF}$, atrial fibrillation; $\mathrm{CAD}$, coronary artery disease.

activation. ${ }^{26}$ Previous studies have shown that decreased albumin increases the general population risk for cardiovascular events. In our research, the levels of albumin in patients with higher RDW were considerably lower.

Therefore, the RAR (RDW-to-albumin Ratio) may give a better overall inflammatory process image than either marker alone, and the AUC of our study intuitively shows so. RAR reflects aortic aneurysms inflammatory activity and could be a useful prognostic progression indicator. RDW-to-albumin Ratio may also be a potential biomarker for new medical treatments that slow thoracic or abdominal aortic aneurysm progression, identifying high-risk patients, and can be beneficial in tailoring the management of patients with thoracic or abdominal aortic aneurysm (eg, more frequent follow-up and/or early intervention). Furthermore, RAR can also be quickly and easily read from the admission laboratory and is not based on volatile blood pressure and heart rate parameters. Therefore, the RAR could be a simple but relatively reliable parameter for risk stratification in patients with thoracic or abdominal aortic aneurysm and could possibly be used before admission to the ICU. The Medicare risk score, the Vascular Study Group of New England risk score, and the Glasgow aneurysm score can be used to predict adverse outcomes in patients undergoing endovascular abdominal aortic aneurysm repair for non-ruptured AAA. However, factors are determined only after surgery and are not satisfactory in clinical practice to predict outcomes.

However, this study has a few drawbacks: Firstly, because the data in this study are all from the MIMIC-III database, making this a retrospective single-center study, there may be potential bias involved. Further in-depth research conducted in multiple centers recruiting more subjects is warranted. Secondly, in the process of variable selection, some variables were not included because of too many missing values in the database, making the model imperfect. Since there were too many missing inflammatory indicators such as CRP in this database, we could not further explain the relationship between RAR and CRP. We have the intention of using our hospital's dataset for 
future verification in the future. Thirdly, the results were mostly descriptive and failed to lead to a causal relationship between the RAR value and prognosis. Although there are some shortcomings, there is no doubt about the prognostic ability of RAR in patients with thoracic or abdominal aortic aneurysms.

\section{Conclusions}

RAR is a prognosis-related risk factor for patients with aortic aneurysms. In light of our findings, we support the further analysis of the associative role of RAR and patients with aortic aneurysms.

\section{Disclosure}

The authors report no conflicts of interest in this work.

\section{References}

1. Patel V, Ghanta RK. Commentary: under pressure: the role of inflammation in aortic aneurysm pathophysiology. $J$ Thorac Cardiovasc Surg. 2020;160(6):1444-1445. doi:10.1016/j.jtcvs.2019.09.037

2. Wanhainen A, Bergqvist D, Boman K, Nilsson TK, Rutegård J, Björck M. Risk factors associated with abdominal aortic aneurysm: a population-based study with historical and current data. J Vasc Surg. 2005;41(3):390-396. doi:10.1016/j.jvs.2005.01.002

3. Gillum RF. Epidemiology of aortic aneurysm in the United States. $J \quad$ Clin Epidemiol. 1995;48(11):1289-1298. doi:10.1016/08954356(95)00045-3

4. Kniemeyer HW, Kessler T, Reber PU, Ris HB, Hakki H, Widmer MK. Treatment of ruptured abdominal aortic aneurysm, a permanent challenge or a waste of resources? Prediction of outcome using a multi-organ-dysfunction score. Eur J Vasc Endovasc Surg. 2000;19 (2):190-196. doi:10.1053/ejvs.1999.0980

5. Thompson MM. Controlling the expansion of abdominal aortic aneurysms. Br J Surg. 2003;90(8):897-898. doi:10.1002/bjs.4280

6. Wilmink TB, Quick CR, Hubbard CS, Day NE. The influence of screening on the incidence of ruptured abdominal aortic aneurysms. $J$ Vasc Surg. 1999;30(2):203-208. doi:10.1016/S0741-5214(99) 70129-1

7. Sakalihasan N, Limet R, Defawe OD. Abdominal aortic aneurysm. Lancet. 2005;365(9470):1577-1589. doi:10.1016/S0140-6736(05) 66459-8

8. Giles KA, Schermerhorn ML, O’Malley AJ. Risk prediction for perioperative mortality of endovascular vs open repair of abdominal aortic aneurysms using the medicare population. J Vasc Surg. 2009;50 (2):256-262. doi:10.1016/j.jvs.2009.01.044

9. Eslami MH, Rybin D, Doros G, Kalish J, Farber A. Comparison of a Vascular Study Group of New England (VSGNE) risk prediction model with the established risk prediction models of in-hospital mortality after elective Abdominal Aortic Aneurysm (AAA) repair. J Vasc Surg. 2014;59(2):568-569.
10. Baas AF, Janssen K, Prinssen M, Buskens E, Blankensteijn J. The Glasgow aneurysm score as a tool to predict 30-day and 2-year mortality in the patients from the Dutch randomized endovascular aneurysm management trial. J Vasc Surg. 2008;47(2):277-281.

11. Golledge J, Muller J, Daugherty A, Norman P. Abdominal aortic aneurysm: pathogenesis and implications for management. Arterioscler Thromb Vasc Biol. 2006;26(12):2605-2613. doi:10.1161/01.ATV.0000245819.32762.cb

12. Mozos I. Mechanisms linking red blood cell disorders and cardiovascular diseases. Biomed Res Int. 2015;2015:682054. doi:10.1155/ $2015 / 682054$

13. Li N, Zhou H, Tang Q. Red blood cell distribution width: a novel predictive indicator for cardiovascular and cerebrovascular diseases. Dis Markers. 2017;2017:7089493. doi:10.1155/2017/7089493

14. Veraldi G, Mezzetto L, Scorsone L, et al. Red blood cell distribution width (RDW) is an independent predictor of post-implantation syndrome in patients undergoing endovascular aortic repair for abdominal aortic aneurysm. Ann Transl Med. 2018;6(23):453.

15. Güngör B, Ozcan K, Ozpamuk Karadeniz F, et al. Red cell distribution width is increased in patients with ascending aortic dilatation. Turk Kardiyol Dern Ars. 2014;42(3):227-235.

16. Grimm G, Haslacher H, Kampitsch T, et al. Sex differences in the association between albumin and all-cause and vascular mortality. Eur J Clin Invest. 2009;39(10):860-865. doi:10.1111/j.13652362.2009.02189.x

17. Johnson AE, Pollard TJ, Shen L, et al. MIMIC-III, a freely accessible critical care database. Sci Data. 2016;3:160035. doi:10.1038/ sdata.2016.35

18. Ernst CB. Abdominal aortic aneurysm. N Engl J Med. 1993;328 (16):1167-1172. doi:10.1056/NEJM199304223281607

19. Schillinger M, Domanovits H, Bayegan K, et al. C-reactive protein and mortality in patients with acute aortic disease. Intensive Care Med. 2002;28(6):740-745. doi:10.1007/s00134-002-1299-1

20. Domanovits H, Schillinger M, Müllner M, et al. Acute phase reactants in patients with abdominal aortic aneurysm. Atherosclerosis. 2002;163(2):297-302. doi:10.1016/S0021-9150(02)00006-0

21. Rehm JP, Grange JJ, Baxter BT. The formation of aneurysms. Semin Vasc Surg. 1998;11(3):193-202.

22. Artemiou P, Charokopos N, Rouska E, et al. C-reactive protein/ interleukin-6 ratio as marker of the size of the uncomplicated thoracic aortic aneurysms. Interact Cardiovasc Thorac Surg. 2012;15 (5):871-877. doi:10.1093/icvts/ivs331

23. Lappé JM, Horne BD, Shah SH, et al. Red cell distribution width, C-reactive protein, the complete blood count, and mortality in patients with coronary disease and a normal comparison population. Clin Chim Acta. 2011;412(23-24):2094-2099. doi:10.1016/j. cca.2011.07.018

24. Folsom AR, Yao L, Alonso A, et al. Circulating biomarkers and abdominal aortic aneurysm incidence: the Atherosclerosis Risk in Communities (ARIC) Study. Circulation. 2015;132(7):578-585. doi:10.1161/CIRCULATIONAHA.115.016537

25. Don BR, Kaysen G. Poor nutritional status and inflammation: serum albumin: relationship to inflammation and Nutrition. Semin Dial. 2004;17(6):432-437. doi:10.1111/j.0894-0959.2004.17603.x

26. LeFevre ML. Screening for abdominal aortic aneurysm: U.S. preventive services task force recommendation statement. Ann Intern Med. 2014;161(4):281-290. doi:10.7326/M14-1204 


\section{Publish your work in this journal}

The International Journal of General Medicine is an international, peer-reviewed open-access journal that focuses on general and internal medicine, pathogenesis, epidemiology, diagnosis, monitoring and treatment protocols. The journal is characterized by the rapid reporting of reviews, original research and clinical studies across all disease areas. The manuscript management system is completely online and includes a very quick and fair peer-review system, which is all easy to use. Visit http://www.dovepress.com/ testimonials.php to read real quotes from published authors.

Submit your manuscript here: https://www.dovepress.com/international-journal-of-general-medicine-journal 